\title{
Borsa ve Makroekonomik Faktörler Arasındaki Etkileşim: BIST100 Örneği*
}

\author{
Seyfettin ÜNAL ${ }^{* *}$
}

\author{
Göksel KARAȘ***
}

\begin{abstract}
$\ddot{O} Z$
Çalışmanın amacı borsa ve makroekonomik değişkenler arasındaki ilişsinin Türkiye özelinde incelenmesidir. Çalışma gerek kullanılan yöntem gerekse veri seti anlamında benzerlerinin bazılarından ayrışmaktadır. Çalışmada bu amaç doğrultusunda makroekonomik faktör olarak kabul edilen GSYH, döviz kuru (Dolar/TL), faiz oranı ve enflasyon ile BIST100 İndeksinin getirisi arasındaki ilişki ampirik olarak analiz edilmiştir. Çalışmada kullanılan çeyreklik veri seti 2003:Ç1 ve 2018:Ç3 arasını kapsamaktadır. Yapılan analizlerde değişkenler arasındaki ilişkinin varlı̆̆ının tespiti amacıyla eşbütünleşme testinin yanı sıra, bu ilişkinin yönünün belirlenmesi amacıyla nedensellik ve değişkenlerde meydana gelen şokların nereden kaynaklandığının tespiti amacıyla da varyans ayrıştırma testleri kullanılmıştır. Analizler sonucunda, BIST100 ile makroekonomik faktörler arasında trende kırılma modeline göre uzun dönemli eşbütünleşik ilişkiye ulaşılmıştır. Nedensellik analizine göre, BIST100 ile faiz oranı arasinda çift yönlü ve anlamlı; BIST100'den GSYH'ye ve yanı sira, BIST100, GSYH ve faiz oranından enflasyona, faiz oranından döviz kuruna, tek yönlü ve anlaml nedensellik ilişkisi bulunmaktadır. Son olarak yapılan varyans ayrı̧̧ırma analizi sonuçlarına göre, çalışma kapsamında elde edilen sonuçların beklentilerle ve literatürle uyumlu olduğu görülmektedir. Buna göre, BIST100 ile faiz oranı ve döviz kurunun en güçlü uzun dönemli açıklayıcı ilişkilere sahip olduğu görülmektedir. Ulaşılan bulgular ışı̆̆ında gerek yatırımcılar gerekse politika yapıcılar açısından önemli çıkarımların olduğu söylenebilir.
\end{abstract}

Anahtar Kelimeler: BIST100, Makroekonomik faktörler, nedensellik, varyans ayrıştırma JEL Sinıflandirması: C32, E44, G23

\section{Interactions Between Stock Market and Macroeconomic Factors: The Case of BIST100}

\begin{abstract}
The aim of this study was to investigate the relationship between stock and Turkey in particular macroeconomic variables. In this study, the relationship between GDP, exchange rate (Dollar / TL), interest rate, and inflation and the return of the BIST100 Index were determined empirically for this purpose. The quarterly data set used in the study covers between 2003: Q1 and 2018: Q3. In the analysis, as well as the cointegration test which used in order to determine the existence of the relationship between the variables, the causality test were used to determine the direction of this relationship, and the variance decomposition test was used to determine where the shock caused in the variables originated. As a result of the analysis, a long-term cointegrated relationship between BIST100 and macroeconomic factors has been reached according to the break
\end{abstract}

\footnotetext{
* Bu çalışmanın ilk versiyonu 11-13 Nisan 2019 tarihlerinde Uşak’ta gerçekleştirilen 7th SCF International Conference on "The Future of the European Union and Turkey-European Union Relations" adlı Sempozyumda tam metin bildiri olarak sunulmuş ve bildiri kitabında basılmıştır.

** Prof. Dr. Dumlupınar Üniversitesi, İBF İşletme Bölümü, seyfettin.unal@dpu.edu.tr, ORCID Bilgisi: 00000002-6248-4317

**** Arş. Grv. Dr. Dumlupınar Üniversitesi, İ̈BF Uluslararası Ticaret ve Finansman Bölümü, göksel.karas@dpu.edu.tr, ORCID Bilgisi: 0000-0003-4091-1258

(Makale Gönderim Tarihi: 26.08.2020 / Yayına Kabul Tarihi:17.03.2021) 
in trend model. In addition, statistically significant bidirectional causality between BIST 100 and interest rate; unidirectional causalities running from BIST100 to GDP and from BIST 100, GDP, and interest rate to inflation, interest rate to exchange rate are detected as a result of causality tests. According to the latest analysis of variance decomposition, the results obtained in the study are in line with the expectations and the literature. Accordingly, it is seen that the interest rate and exchange rate have the strongest long-term explanatory relations with BIST100. In the light of the findings, it can be said that there are important implications for both investors and policymakers.

Key Words: BIST100, Macroeconomic factors, causality, variance decomposition

JEL Classifications: C32, E44, G23

\section{GíRiș}

1980'lerde liberalleşme ile birlikte başlayan ve öncelikle uluslararası ticarette kendini gösteren küreselleşme olgusu hızla tüm alanlara yayılmıştır. Hemen ardından 1990'ların başında Sovyet Bloğunun dağılmasıyla süreç daha da ivme kazanmıştır. Neredeyse eş zamanlı olarak bilişim teknolojilerinde yaşanan baş döndürücü gelişmeler, hayatın her alanında etkisini göstermiştir. Bu gelişmelerden en çok nasibini alanların başında finansal hizmetler sektörü gelmektedir. Gerek veri ve bilgiye erişme gerekse her an her yerde hızlı ve etkin işlem yapabilme imkânları sayesinde finansal hizmetler sektöründe çok hızlı gelişmeler kaydedilmiştir. Böylece, küreselleşme ile başlayıp, artan finansal entegrasyonla devam eden süreçte fon akımları hayli etkileyici hacimlere ulaşmıştır. Söz konusu sermaye akımlardan pay alma yarışında gelişmekte olan ülkeler de yer almaya çalışmaktadır. Bir tarafta kendisine portföy çeşitlendirmesinin de sağlayacağ 1 avantajlarla yüksek getiri arayan, özellikle gelişmiş ülkelerin artan sermaye birikimi; diğer tarafta ise, yüksek getiri potansiyeline sahip gelişmekte olan ülkelerin bâkir piyasaları karşımıza çıkmaktadır.

Sermaye akımlarının bilinen iki formu doğrudan yatırımlar ve portföy yatırımlarıdır. Genel kanı ve literatürdeki ampirik bulgular doğrudan yatırımların geldiği ülkeye sağladığı katkılar konusunda hayli olumludur. Diğer taraftan, portföy yatırımlarının genellikle kısa dönemli olduğu görülür ve geldiği ekonomiye faydaları ise sorgulanmaya açıktır. Hatta sıcak para olarak kabul edilen portföy yatırımlarının ani çıkışlarının bir hayli yıkıcı etkiler yaratabildiği görülmüştür. Türkiye yüksek cari açık problemi olan ve doğrudan yatırımların söz konusu açı̆̆ kapatmakta yetersiz kalması nedeniyle de sıcak para akımlarına ihtiyaç duyan bir ekonomidir. Ayrıca, hali hazırda yeterli derinliğe ulaşamamış Türkiye hisse senedi piyasasında \%65-70 düzeyinde yabancı yatırımcı ağırlığı olduğu da bilinmektedir. $\mathrm{Bu}$ şartlar altında Türkiye hisse senedi piyasasının içsel ve dişsal gelişmelere karşı ne denli hassas olduğunu öngörmek pek de zor değildir. Dolayısıyla, yerel ekonomik ve finansal değişkenlerin hisse senedi piyasası üzerindeki etkileri sıklıkla araştırma konusu olmaktadır. Elbette, fon akımlarını etkileyen faktörler sadece yerel -aynı zamanda yerel ya da çekici olarak da adlandırılan- unsurlar değildir. Dişsal -aynı zamanda global yada itici olarak da adlandırılan-pek çok unsurun da etkili olduğu bilinmektedir. Dolayısıyla, oldukça fazla sayıda ve aralarında bir hayli komplike ilişkilerin söz konusu olduğu değişkenlerin etkisine maruz kalan sermaye akımlarının yönünü ve zamanını öngörmek hiç kolay olmamaktadır. 
Finans literatürüne bakıldığında varlıkların getirilerindeki değişiklikleri açıklamaya yönelik iki temel yaklaşım bulunduğu görülmektedir. Bu yaklaşımlar Sermaye Varlıkları Fiyatlama Modeli (CAPM) ve Arbitraj Fiyatlama Modeli (APM)'dir. Markowitz (1952) tarafından etkin portföy seçimine yönelik önerilen CAPM, Sharpe (1964), Mossin (1966) ve Lintner (1969) tarafindan da geliştirilmiştir. CAPM modelinde, getirileri etkileyen yalnızca bir faktör ele alınmaktadır. $\mathrm{Bu}$ faktör de pazar faktörüdür. $\mathrm{Bu}$ durum piyasalarda yaşanan gelişmelere bakıldığında getirileri etkileyen diğer faktörlerin dikkate alınmamasına neden olmaktadır (Altınbaş vd.. 2015: 33). Bu nedenle getirileri etkileyen faktörlerin belirlenebilmesi amaciyla daha doğru analizlerin yapılabilmesi için pazar faktörünü dikkate alan tek faktörlü modeller yerine diğer faktörleri de analize dahil eden çok faktörlü modeller geliştirilmiştir. Bu modellerden birisi Roll ve Ross (1980) tarafından geliştirilen APM'dir. APM'ye göre hisse senetlerinin getirilerinde yaşanan değişimler, makroekonomik faktörlerde gözlenen değişimlerden kaynaklanmaktadır. Makroekonomik değişkenler ise çok faktörlü bir modellemeyi sağlamakta ve CAPM'ın eksik yönünü tamamlamaktadır.

Hisse senedi fiyatları hem yurt içi hem de yurt dışı gelişmelere karşı duyarlıdır. $\mathrm{Bu}$ duyarlılı̆̆ın oluşmasında birçok makroekonomik faktör yer almaktadır. Bu bağlamda yatırımcılar açısından hisse senetleri ile makroekonomik değişkenler arasındaki ilişkinin varlığı ve derecesi son derece önemli bir konu olmaktadır. Literatürde bu ilişkinin analizi ile ilgili çok sayıda çalışma bulunmaktadır. Ekonominin farklı boyutlarının yansitılabilmesi ve hisse senetlerinde yaşanan değişmelerin açıklanabilmesi amacıyla kullanılabilecek makroekonomik faktörler benzer çalışmalarda farkl11ık gösterebilmektedir. Literatürde yer alan çalışmalarda faktörler, gayri safi yurtiçi hasıla (GSYH), sanayi üretim endeksi, sabit sermaye oluşumu, işsizlik oranı, toplam tasarruflar, faiz oranı, LIBOR, enflasyon oranı, petrol ve altın fiyatları, döviz kuru ve döviz rezervleri sıklıkla kullanılmaktadır.

Çalışma kapsamında Türkiye piyasası özelinde BIST100'ün getirisinde değişime neden olan makroekonomik faktörlerin araştırılması amaçlanmaktadır. Çalışma benzerlerinin bazılarından, gerek kullanılan yöntem gerekse veri seti anlamında ayrışmaktadır. Literatürdeki bazı benzerlerini ise son verilerle güncellemek amaçlanmaktadır. Böylelikle, geçmiş çalışmalarda ulaşılan ampirik bulguların teyidi ya da olası ayrışmaların tespit ve tartışılması imkânı doğabilecektir. Çalışmada, BIST100 ile makroekonomik değişkenler olarak seçilen ve literatürde yaygın olarak kullanılan döviz kuru, faiz oranı, enflasyon ve GSYH arasındaki ilişki 2003:Q1 ve 2018:Q3 dönemi için araştırılmaktadır. Amaca yönelik olarak öncelikle Augmented Dickey Fullar (ADF) ve Kwiatkowski-PhillipsSchmidt-Shin (KPSS) birim kök testleri ile yapısal kırılmayı dikkate alan ZivotAndrews yapısal kırılmalı birim kök testi uygulanmış; ardından Gregory-Hansen eşbütünleşme analizi ve Granger nedensellik analizi gerçekleştirilmiştir. Çalışmanın takip eden ikinci bölümünde literatür incelemesi bulunmakta olup; üçüncü bölümde veri ve yönteme yer verilmektedir. Analiz bulgularının yer aldığ1 
dördüncü bölümün ardından çalışma, sonuç ve değerlendirmenin sunulduğu beşinci bölüm ile sonlanmaktadır.

\section{LITERATÜR INNCELEMESI}

Hisse senedi fiyatlarıyla belirli makroekonomik değişkenler arasındaki ilişkilerin incelendiği birçok çalışma bulunmaktadır. Nitekim Aggarwal (1981) ABD piyasasında döviz kuru ile borsa arasında pozitif ve anlamlı bir ilişki bulmuştur. Fama ve Gibbons (1982) beklenen enflasyonla hisse senedi fiyatları arasında negatif ilişki bulurken, Fama (1990) hisse senedi getirilerinin çeşitliliğinin büyük bir kısmının, zamanla değişen beklenen getiriler ve ekonomik faaliyetlerin tahminleri ile açıklanabileceği sonucuna ulaşmıştır. Benzer şekilde Darrat (1990) bütçe açıkları, uzun dönem bono oranları, sanayi üretimi ve faiz oranlarındaki hareketliliğin hisse senetleri fiyatları üzerinde etkisinin olduğu sonucuna ulaşmıştır. Fernandez-Arias (1994) gelişmekte olan ülkelerde, dış getiri ile ülke riskine göre ayarlanan iç getiriler arasındaki arbitraj koşullarına dayalı analitik bir uluslararası portföy yatırım modeli sunmak amacıyla yapmış olduğu çalışmada, sermaye girişlerinin büyük ölçüde olumlu uluslararası faiz oranlarına bağımlı olduğu ve sermaye girişlerinin artmasının, büyük ölçüde yerel faktörlerin aksine sanayi ülkelerindeki düşük getirilerden kaynaklandığını ifade etmektedir. Cheung ve Ng (1997) Kanada, Almanya, İtalya, Japonya ve ABD gibi beş ulusal borsa endeksleri ile petrol fiyatı, reel tüketim, para arzı ve çıtı gibi makroekonomik değişkenler arasında uzun vadeli ilişki bulmuştur. Wang ve Shen (1999) Tayvan üzerinde yapmış olduğu çalışmada döviz kuru ile borsa getirileri arasında bir ilişkinin olduğunu ve liberalizasyon sürecinde döviz kurunun ve borsa getirilerinin arttığını ifade etmektedir. Muradoğlu vd. (1999) makroekonomik değişkenlerin borsa getirileri üzerindeki etkilerinin kriz öncesi, krizi sıras1 ve kriz sonrasında değiştiği ve faiz oranlarıyla borsa getirileri arasında negatif bir ilişkinin olduğu sonucuna ulaşmıştır. Muradoğlu vd. (2000) Türkiye'nin de içinde bulunduğu 19 gelişmekte olan piyasada makroekonomik faktörlerle borsa getirileri arasındaki ilişkiyi incelediği çalışmada, dünya piyasaları ile bütünleşme ve borsanın büyüklüğ̈̈ne bağl1 olarak makroekonomik faktörler ile borsa getirileri arasında iki yönlü bir nedenselliğin bulunduğunu ifade etmektedir. Bilson vd. (2001) ise borsa getirileri üzerinde politik riskin etkisini analiz etmiştir. Buna göre, borsa getirileri ile politik risk arasında pozitif bir ilişki bulunmaktadır. Abugri (2008), dört Latin Amerika ülkesinde döviz kurları, faiz oranları, endüstriyel üretim ve para arzı gibi seçilmiş makroekonomik faktörlerin piyasa iadelerini önemli ölçüde açıklayıp açıklamayacağını araştırmaktadır. Çalışma sonucunda makroekonomik faktörlerin pazarları değişen anlam ve büyüklüklerde etkilediği bulunmuştur. Açıkalın vd. (2008) İstanbul Menkul Kiymetler Borsası (İMKB) ile makroekonomik değişkenler arasındaki ilişkiyi incelemiştir. Nedensellik testleri sonucunda, makroekonomik değişkenlerden GSYIH, döviz kuru ve cari işlemler dengesindeki değişiklikler ile İMKB endeksi arasında tek yönlü ilişsi bulunmuştur. Çalışmada beklentilerin aksine, borsa endeksindeki değişiklikler faiz oranlarını etkilemektedir. Tangjitprom (2012), makroekonomik değişkenlerin bazı 
gecikmeler için ayarlama yaptıktan sonra hisse senedi getirisini önemli ölçüde açıklayabileceğini ortaya koymaktadır. Pramod-Kumar ve Puja (2012), borsa ile makroekonomik faktörler arasındaki ilişkinin yeniden incelenmesinin yatırımcılar için uygun ve gerekli olacağını belirtmektedir. Yatırımcılar, makroekonomik değişkenler ile hisse senedi piyasası arasındaki ilişkiden haberdar olmalı ve böylece daha ihtiyatlı ve verimli yatırımlar yapabilmelidir. Shafana (2014), Sri Lanka'da Telekom sektörü dışındaki tüm sektörel endekslerin değişkenliğini açıklamak için döviz kuru, faiz oranı ve enflasyon oranının standart değişkenler olduğunu göstermiştir. Barakat vd. (2016), Mısır ve Tunus'taki makroekonomik faktörler ile borsa arasındaki ilişkiyi araştırmıştır. Piyasa endeksi ile faiz oranı, tüketici fiyat endeksi, döviz kuru ve para arzı arasında nedensel bir ilişki olduğunu bulmuşlardır. Yeşildağ (2016) Arbitraj Fiyatlama Modeli ile makroekonomik faktörlerin Borsa İstanbul'da mevcut olan endekslerin getirileri üzerindeki etkilerini araştırdığ1 çalışmasında, endeks getirilerinin tümünün piyasa faiz oranlarına duyarlı oldukları ayrıca, M2 para arzı, enflasyon oranı, ihracatın ithalatı karşılama oranı, kapasite kullanım oranları ve altın fiyatlarının, hisse senedi endeks getirilerini belirlemede etkili olduğu sonucuna ulaşmıştır. Sutrisno (2017) Endonezya özelinde makroekonomik faktörler ile sektörel endeksler arasındaki ilişkiyi analiz etmiştir. Buna göre, faiz oranının, enflasyon oranının ve döviz kurunun aynı anda Endonezya'daki sektör endeksleri üzerinde önemli bir etkiye sahiptir. Alper ve Kara (2017) Türkiye'de hisse senede getirileri ile makroekonomik faktörler arasındaki ilişkiyi incelemiştir. Çalışmada, reel hisse senedi getirilerinin çoğunlukla kendi gecikmeli değerlerinden etkilendiği ve makroekonomik faktörlerin etkisinin oldukça sınırlı kaldığı sonucuna ulaşılmıştır. Sadeghzadeh ve Elmas (2018) BIST özelinde makroekonomik faktörlerin hisse senedi getirileri üzerindeki etkisini incelemiştir. Yapılan analizler sonucunda BIST'de hisse senedi getirilerini en çok etkileyen makroekonomik faktörlerin; VIX korku endeksi, tüketici güven endeksi ve BIST işlem miktarı olduğu sonucuna ulaşılmıştır. Şekeroğlu vd. (2019) BIST özelinde makroekonomik faktörlerden enflasyon ve dış ticaret açığının hisse senedi getirileri üzerindeki etkisini araştırmıştır. Yapılan analizler sonucunda değişkenler arasında uzun dönemli eşbütünleşik bir ilişkinin olduğu sonucuna ulaşılmıştır. $\mathrm{Bu}$ çalışmalar, makroekonomik değişkenlerin borsa performansını açıklayabileceği sonucuna varmıştır. Bazı makroekonomik değişkenlerin etkisi bir piyasadan diğerine ve bir dönemden diğerine farkl1lı gösterebilir. Literatürde yer alan çalışmalara bakıldığında genelde zaman dilimi daha eski tarihe dayanmaktadır. Bu açıdan çalışmanın, 2018 yılını kapsaması nedeniyle ve özellikle de 2018 yılında Türkiye'nin de içinde bulunduğu ticaret savaşları ve kur saldırısının etkilerinin görülmesi açısından literatüre katkı sağlayacağı düşünülmektedir.

\section{VERİ VE YÖNTEM}

$\mathrm{Bu}$ çalışma, BIST100 ile döviz kuru, faiz oranı, enflasyon ve GSYH arasındaki ilişkiyi incelemektedir. BIST100 veri seti Borsa İstanbul'dan diğer değişkenlere ait veri seti ise Türkiye Cumhuriyet Merkez Bankası veri tabanından elde edilmiştir. Veri seti 2003'ün ilk çeyreğinden 2018'in üçüncü çeyreğine kadar 
devam etmektedir. İktisat literatüründe, ulusal ve küresel makroekonomik göstergeler ile hisse senedi piyasası getirileri arasındaki etkileşimler, çeşitli ekonometrik modeller kullanılarak incelenmiştir (örneğin, bknz. Kwon \& Shin, 1999; Bilson vd., 2001; Abugri, 2008). Bu çalışma, Türkiye'deki makroekonomik değişkenler ile BIST100 getirileri arasındaki ilişkiyi incelemeyi amaçlamaktadır. Literatürde makroekonomik göstergeler, borsa getirilerindeki değişikliklerin açıklayıcısı olarak kullanılmaktadır. Buradan hareketle, çalışmada kullanılacak ekonometrik model aşağıdaki gibi oluşturulmuştur.

$$
B I S T 100_{t}=\beta_{0}+\beta_{1} E X C_{t}+\beta_{2} I N T_{t}+\beta_{3} I N F_{t}+\beta_{4} G D P_{t}+\varepsilon_{t}
$$

Modelde BIST100 Borsa İstanbul endeksini, EXC döviz kurunu, INT faiz oranını, INF enflasyonu ve GDP Gayrisafi Yurtiçi Hasılayı ifade etmektedir. Ekonometrik analizler yardımıyla, borsa getirileri ile döviz kuru, faiz oran1, enflasyon ve GSYİH arasındaki ilişki ve yönü ortaya konulmaya çalışılmıştır. Geske ve Roll (1983)'e göre modelde kullanılan makroekonomik göstergeler arasında yer alan döviz kurlarının, ticaretin etkisiyle hisse senedi fiyatlarını etkilediği gösterilmiştir. Bununla birlikte, Fama ve Schwert (1977) ve Geske ve Roll (1983)'ün yapmış olduğu çalışmalarında hisse senedi getirileri ve enflasyon arasındaki ilişki oldukça tartışmalıdır. Yapılan ampirik araştırmalara bakıldığında, ağırlıklı olarak hisse senedi getirileri ve enflasyon arasında negatif bir ilişki olduğu görülmektedir. Aynı zamanda Chen vd. (1986) tarafından yapılan çalışmada, enflasyonda bir artışın, borsa değerlemesinde kullanılan iskonto oranlarını yükselteceği tahmin edilmiştir. Artan iskonto oranının etkisi, yalnızca firmaların nakit akışlarının aynı oranda artması durumunda toplam olarak sıfirlanabilmektedir. Diğer yandan, sözleşmelerin nominal olması ve buna göre düzeltilememesi durumunda etki olumsuz olacaktır. Dolayısıyla, bu bağlamda, nominal faiz oranlarının hisse senedi fiyatları üzerindeki etkisinin de olumsuz olması beklenmektedir. Fama (1990)' ya göre de reel iktisadi faaliyetin seviyesinin, piyasa öncesi nakit akışları üzerinde olumlu bir etkisinin olması ve dolayısıyla hisse senedi fiyatlarını aynı yönde etkilemesi beklenmektedir.

Çalışmada öncelikle, logaritması alınan BIST100, EXC, INT, INF ve GDP değişkenlerin durağanlıkları, ADF ve KPSS birim kök testleri kullanılarak sınanmıştır. Ardından yapısal kırılmaları dikkate alan Zivot-Andrews (1992) yapısal kırılmalı birim kök testi uygulanmıştır. Birim kök testinden sonra analizde kullanılan değişkenler arasında ilişkinin var olup olmadığının analizi için GregoryHansen (1996) yapısal kırılmalı eşbütünleşme testi uygulanmış, sonrasında tespit edilen ilişkinin yönünün belirlenmesi amacıyla Granger nedensellik analizi yapılmış ve ardından değişkenlerde meydana gelen şokların etkilerinin incelenebilmesi için varyans ayrıştırma analizi yapılmıştır.

\section{AMPIRIK BULGULAR}

Metodoloji bölümünde bahsi geçen analizlerin sonucundaki bulgulara aşağıda yer verilmektedir. Buna göre, öncelikle durağanlık analizi sonuçları; ardından eşbütünleşme analizi sonuçları sunulmuştur. Daha sonra, nedensellik ve son olarak ise varyans ayrıştırma analizi bulguları incelenmiştir. 


\section{A. Durağanlık Analizi}

Ekonometrik analizlerde değişkenlerin zaman serileri olması durumunda serilerin aynı derecede durağan olup olmadıkları önemlidir. Çünkü analizde kullanılan serilerin aynı derecede durağan olmaması durumunda seriler arasında kurulacak regresyon modellerinde sahte regresyon sorunu ortaya çıabilmektedir (Gujarati ve Porter, 2012: 748). Bu nedenle analize öncelikli olarak analizde kullanılacak serilerin durağanlığının test edilmesiyle başlanmıştır.

Serilerin varyanslarının küçültülebilmesi amacıyla öncelikle doğal logaritmaları alınmıştır. Ardından bu değişkenlerin durağanlıklarının tespiti için genel kullanıma sahip olduğundan dolayı ADF ve KPSS birim kök testleri uygulanmıştır. ADF ve KPSS birim kök testi sonuçları Tablo 1'de yer almaktadır.

Tablo 1: ADF ve KPSS Birim Kök Testi Sonuçları

\begin{tabular}{|c|c|c|c|c|c|c|c|}
\hline & \multirow{2}{*}{ Model } & \multicolumn{2}{|c|}{ ADF } & \multicolumn{4}{|c|}{ KPSS } \\
\hline & & t-istatistik* & $\mathbf{p}$ & test istatistiğ $i^{* *}$ & $\% 1$ & $\% 5$ & $\% 10$ \\
\hline LNBIST100 & & $-1.7091(3)$ & 0.4216 & $0.9499(6)$ & 0.739 & 0.463 & 0.347 \\
\hline LNEXC & & $-1.0118(1)$ & 0.7440 & $0.7660(5)$ & 0.739 & 0.463 & 0.347 \\
\hline LNGDP & & $0.5955(6)$ & 0.9884 & $1.0146(6)$ & 0.739 & 0.463 & 0.347 \\
\hline LNINF & & $2.3739(8)$ & 1.0000 & $1.0275(6)$ & 0.739 & 0.463 & 0.347 \\
\hline LNINT & & $-2.5724(1)$ & 0.1041 & $0.8960(3)$ & 0.739 & 0.463 & 0.347 \\
\hline & Sabitli Model & & & & & & \\
\hline$\Delta$ LNBIST100 & & $-5.9928(1)$ & 0.0000 & $0.3700(2)$ & 0.739 & 0.463 & 0.347 \\
\hline$\triangle \mathrm{LNEXC}$ & & $-10.0339(0)$ & 0.0000 & $0.1983(3)$ & 0.739 & 0.463 & 0.347 \\
\hline$\triangle \mathrm{LNGDP}$ & & $-3.1267(3)$ & 0.0300 & $0.1419(12)$ & 0.739 & 0.463 & 0.347 \\
\hline$\Delta \mathrm{LNINF}$ & & $-5.6282(0)$ & 0.0000 & $0.3976(3)$ & 0.739 & 0.463 & 0.347 \\
\hline$\Delta \mathrm{LNINT}$ & & $-4.4055(0)$ & 0.0007 & $0.3292(8)$ & 0.739 & 0.463 & 0.347 \\
\hline LNBIST100 & & $-2.6799(3)$ & 0.2485 & $0.2034(3)$ & 0.216 & 0.146 & 0.119 \\
\hline LNEXC & & $-0.5609(9)$ & 0.9773 & $0.2390(5)$ & 0.216 & 0.146 & 0.119 \\
\hline LNGDP & & $-1.8408(10)$ & 0.6704 & $0.3166(0)$ & 0.216 & 0.146 & 0.119 \\
\hline LNINF & & $-0.2920(8)$ & 0.9890 & $0.2357(5)$ & 0.216 & 0.146 & 0.119 \\
\hline LNINT & & $-1.0645(1)$ & 0.9265 & $0.2604(5)$ & 0.216 & 0.146 & 0.119 \\
\hline & $\begin{array}{l}\text { Sabitli Trendli } \\
\text { Model }\end{array}$ & & & & & & \\
\hline$\Delta$ LNBIST100 & & $-6.2888(1)$ & 0.0000 & $0.0860(1)$ & 0.216 & 0.146 & 0.119 \\
\hline$\triangle \mathrm{LNEXC}$ & & $-4.5454(8)$ & 0.0032 & $0.0673(5)$ & 0.216 & 0.146 & 0.119 \\
\hline$\triangle \mathrm{LNGDP}$ & & $-3.8672(5)$ & 0.0201 & $0.0889(4)$ & 0.216 & 0.146 & 0.119 \\
\hline$\Delta \mathrm{LNINF}$ & & $-5.9481(0)$ & 0.0000 & $0.1459(6)$ & 0.216 & 0.146 & 0.119 \\
\hline$\Delta$ LNINT & & $-5.4259(0)$ & 0.0002 & $0.0638(2)$ & 0.216 & 0.146 & 0.119 \\
\hline
\end{tabular}

Not: *ADF birim kök testinde t-istatistik değerlerinin yanında parantez içinde yer alan değerler Akaike Bilgi Kriteri tarafından otomatik olarak belirlenen gecikme sayılarını göstermektedir.

**KPSS birim kök testinde test istatistik değerlerinin yanında parantez içinde yer alan değerler bandwidth değerleri olup, Newey-West kriteri tarafından belirlenen değerlerdir.

Tablo 1'de ADF ve KPSS birim kök testi sonuçları yer almaktadır. Buna göre analizde kullanılacak tüm değişkenler düzey değerlerinde durağan değildir. Serilerin durağanlaştırılabilmesi için sonraki aşamada serilerin birinci dereceden farkları alınmış ve tekrar analiz edilmiştir. Birinci dereceden farkları alınarak yapılan birim kök testi sonuçlarına göre, değişkenlerinin I(1)'de durağanlaştığ1 görülmektedir.

ADF ve KPSS testleri serilerde belirli dönemlerde meydana gelen kırılmaları dikkate almamaktadır. $\mathrm{Bu}$ testlerin yanı sıra değişkenler arasında 
yapılacak olan tahminde ilgili dönemlerde meydan gelen bir yapısal kırılmanın etkisinin belirlenmesi amaciyla Zivot-Andrews (1992) yapısal kırılmalı birim kök testi kullanılmıştır. Zivot ve Andrews (1992) kırılmayı içsel olarak algılamaktadır. Yani kırılmanın zamanının bilinmediği varsayılmaktadır (Sevüktekin ve Çınar, 2014: 445). Zivot-Andrews birim kök testi 3 modele dayalı olarak yapılmaktadır (Zivot ve Andrews, 1992: 253-254). Model A, sabitte kırılmay1; Model B, trendde kırılmayı ve Model C ise hem sabit hem de trendde kırılmayı modellemektedir. Buna göre, çalışma kapsamında yapılan Zivot-Andrews yapısal kırılmalı birim kök testi sonuçları Tablo 2'de verilmektedir.

Tablo 2: Zivot-Andrews Yapısal Kırılmalı Birim Kök Testi Sonuçları

\begin{tabular}{cccccccc}
\hline \multirow{2}{*}{ Değişken } & \multirow{2}{*}{ Model } & \multirow{2}{*}{ Gecikme Sayısı } & \multirow{2}{*}{ Kirılma Tarihi } & \multirow{2}{*}{ Test İst. } & \multicolumn{3}{c}{ Kritik Değerler } \\
& & & & & $\mathbf{1 \%}$ & $\mathbf{5 \%}$ & $\mathbf{1 0 \%}$ \\
\hline \multirow{2}{*}{ LNBIST100_SA } & $\mathrm{A}$ & 3 & $2014 \mathrm{Q} 3$ & -3.186 & -5.34 & -4.93 & -4.58 \\
& $\mathrm{C}$ & 3 & $2007 \mathrm{Q} 4$ & -4.084 & -5.57 & -5.08 & -4.82 \\
\hline \multirow{2}{*}{ LNEXC_SA } & $\mathrm{A}$ & 1 & $2016 \mathrm{Q} 3$ & -3.799 & -5.34 & -4.93 & -4.58 \\
& $\mathrm{C}$ & 1 & $2016 \mathrm{Q} 2$ & -5.006 & -5.57 & -5.08 & -4.82 \\
\hline \multirow{2}{*}{ LNINT_SA } & $\mathrm{A}$ & 1 & $2009 \mathrm{Q} 1$ & -3.491 & -5.34 & -4.93 & -4.58 \\
& $\mathrm{C}$ & 1 & $2013 \mathrm{Q} 3$ & -3.566 & -5.57 & -5.08 & -4.82 \\
\hline \multirow{2}{*}{ LNINF_SA } & $\mathrm{A}$ & 2 & $2014 \mathrm{Q} 4$ & 0.227 & -5.34 & -4.93 & -4.58 \\
& $\mathrm{C}$ & 2 & $2016 \mathrm{Q} 2$ & -1.954 & -5.57 & -5.08 & -4.82 \\
\hline \multirow{2}{*}{ LNGDP_SA } & $\mathrm{A}$ & 4 & $2008 \mathrm{Q} 3$ & -5.181 & -5.34 & -4.93 & -4.58 \\
& $\mathrm{C}$ & 4 & $2008 \mathrm{Q} 3$ & -4.859 & -5.57 & -5.08 & -4.82 \\
\hline
\end{tabular}

Tablo 2'de Model A serilerin sabitte kırılmayı, Model C ise sabit ve trendde kırılmayı göstermektedir. Tablo 2'de yer alan analiz sonuçlarına göre; her iki model için de test istatistiğinin mutlak değerlerinin GSYH dışında, kritik değerden küçük olması nedeniyle GSYH dışındaki değişkenler durağan değildir, yani seriler birim kök içermektedir. Bundan dolayı her iki modele göre de bahsi geçen kırılma tarihleri ile yapısal kırılmalı birim kök temel hipotezi kabul edilmektedir. Bu sonuçlar ADF ve KPSS testlerinden elde edilen sonuçları desteklemektedir.

\section{B. Eşbütünleşme Analizi}

Gregory ve Hansen (1996) yapmış oldukları çalışmada değişkenler arasındaki eşbütünleşik ilişkinin tespitinde tek yapısal kırılmayı dikkate alan bir test geliştirmiştir. Buna göre yapısal kırılmalar önsel olarak değil, içsel olarak belirlenmektedir. Yapısal kırılmanın varlığına izin veren Gregory-Hansen Eşbütünleşme Testinde sabitte, trendde ve rejimde meydana gelen değişmeye göre üç farklı model aracılığıyla değişkenler arasındaki uzun dönemli eşbütünleşik ilişki araştırılabilmektedir (Gregory ve Hansen, 1996: 102-103).

$\mathrm{Bu}$ üç model için Phillips test istatistikleri (Zt ve Za) ile ADF test istatistiği (ADF) hesaplanmaktadır. $\mathrm{Bu}$ test istatistiklerinin minimum olduğu tarih eşbütünleşme testinin uygun kırılma tarihini göstermektedir. Bu testte hesaplanan test istatistiklerinin anlamlı olup olmadıklarının karar verilebilmesi için Gregory ve 
Hansen (1996)'in çalışmalarında yer verdikleri kritik değerler ile karşılaştırılmaktadır. Analiz sonucunda elde edilen test değerlerinin kritik değerlerden büyük olması durumunda yapısal kırılmayla birlikte seriler arasında eşbütünleşme ilişkisinin var olduğu sonucuna ulaşılmaktadır (Öztürk vd., 2013: 68). Tablo 3 'te Gregory-Hansen eşbütünleşme testi sonuçlarına yer verilmektedir.

Tablo 3: Gregory-Hansen Eşbütünleşme Testi Sonuçları

\begin{tabular}{|c|c|c|c|c|c|}
\hline \multirow{2}{*}{ Model } & \multirow{2}{*}{ Kırılma Dönemi } & \multirow{2}{*}{ ADF İstatistiği } & \multicolumn{3}{|c|}{ Kritik Değerler } \\
\hline & & & $1 \%$ & $5 \%$ & $10 \%$ \\
\hline Model 1: Sabitte Kırılma & 2008Q3 & -4.33 & -6.05 & -5.56 & -5.31 \\
\hline Model 2: Trendde Kırılma & 2008Q1 & -5.83 & -6.36 & -5.83 & -5.59 \\
\hline Model 3: Rejimde Kırılma & 2008Q1 & -6.15 & -6.92 & -6.41 & -6.17 \\
\hline
\end{tabular}

Not: Kritik değerler Gregory ve Hansen (1996: 109)'dan alınmıştır. Gecikme sayıları Akaike Bilgi Kriteri tarafindan 0 (sıfir) olarak seçilmiştir.

Tablo 3'te yer alan sonuçlara göre, Model 1 ve Model 3'e göre değişkenler arasında uzun dönemli eşbütünleşme ilişkisinin bulunmadığı, Model 2'de ise 0.05 anlamlılık düzeyinde eşbütünleşme ilişkisinin bulunduğu görülmektedir. Dolayısıyla değişkenler arasındaki eşbütünleşik ilişkinin olduğu sonucuna ulaşılabilir.

\section{Nedensellik Analizi}

Eşbütünleşme analizi ile yukarıda da bahsedildiği üzere değişkenler arasındaki eşbütünleşik ilişki analiz edilmektedir. Yapılan analiz sonucunda modelde yer alan değişkenler arasında eşbütünleşik ilişkinin varlığ1 tespit edilmiştir. Ardından bu ilişkinin yönünün tespit edilmesi önem arz etmektedir. Bu amaçla da nedensellik analizinin yapılması gerekmektedir. Değişkenler arasındaki nedensellik ilişkisinin tespiti amacıyla Granger (1986) tarafindan geliştirilen Granger nedensellik testiyle, değişkenler arasında nedensellik ilişkisinin var olup olmadığının ve ilişkinin yönü belirlenebilmektedir (Barışık ve Demircioğlu, 2006: 76). Granger nedensellik testi değişkenler arasındaki kısa dönemli ilişkiyi gösterirken, hata düzeltme modeli sonucu elde edilen bulgular ise değişkenler arasındaki uzun dönemli ilişkiyi göstermektedir. Nedensellik analizi yapılırken tüm değişkenlerin durağan olduğu birinci farkları analize dahil edilmiştir. Tablo 4'te kısa dönem nedenselliği gösteren Granger nedensellik testi sonuçları yer almaktadır.

Tablo 4: Granger Nedensellik ve Hata Düzeltme Modeli Testi Sonuçları

\begin{tabular}{lllll}
\hline $\begin{array}{l}\text { Bağımlı } \\
\text { Değişken }\end{array}$ & $\begin{array}{l}\text { Bağımsız } \\
\text { Değişken }\end{array}$ & $\begin{array}{l}\text { Ki-Kare } \\
\text { İstatistiği }\end{array}$ & $\begin{array}{l}\text { Serbestlik } \\
\text { Derecesi }\end{array}$ & $\begin{array}{l}\text { Olasılık } \\
\text { Değeri }\end{array}$ \\
\hline \multirow{4}{*}{ BIST100 } & Döviz Kuru & 4,184 & 3 & 0,242 \\
& GSYH & 4,509 & 3 & 0,212 \\
& Enflasyon & 3,086 & 3 & 0,379 \\
& Faiz Oranı & 4,709 & 3 & 0,194 \\
\hline \multirow{4}{*}{ Döviz Kuru } & BIST100 & 3,420 & 3 & 0,331 \\
& GSYH & 1,847 & 3 & 0,605 \\
& Enflasyon & 0,327 & 3 & 0,955 \\
& Faiz Oranı & 3,844 & 3 & 0,279 \\
\hline \multirow{3}{*}{ GSYH } & BIST100 & 10,721 & 3 & $0,013^{* *}$ \\
& Döviz Kuru & 2,031 & 3 & 0,566 \\
& Enflasyon & 2,565 & 3 & 0,464 \\
\hline Enflasyon & Faiz Oranı & 7,296 & 3 & $0,063^{* * *}$ \\
\hline
\end{tabular}




\begin{tabular}{llllc}
\hline & Döviz Kuru & 0,685 & 3 & 0,877 \\
& GSYH & 25,010 & 3 & $0,000^{*}$ \\
& Faiz Oran1 & 14,314 & 3 & $0,003^{*}$ \\
\hline \multirow{3}{*}{ Faiz Oranı } & BIST100 & 11,158 & 3 & $0,011^{* *}$ \\
& Döviz Kuru & 1,954 & 3 & 0,582 \\
& GSYH & 2,057 & 3 & 0,561 \\
& Enflasyon & 2,943 & 3 & 0,401 \\
\hline
\end{tabular}
bulunduğunu göstermektedir.

Tablo 4'te yer alan sonuçlara göre GSYH ve faiz oranından enflasyona \%1 anlamlı11k düzeyinde, BIST100'den GSYH, enflasyon ve faiz oranına kısa dönemli tek yönlü $\% 5$ anlamlılık düzeyinde nedensellik bulunurken, faiz oranından GSYH'ye kısa dönemli tek yönlü $\% 10$ anlamlılık düzeyinde nedensellik bulunmuştur.

\section{Varyans Ayrıştırma Analizi}

VAR modeli sonucunda elde edilen varyans ayrıştırma analizi, bir değişkenin kendi şoklarından kaynaklanan değişimler ile diğer değişkenlerin şoklarından kaynaklanan değişimlerin oranını göstermektedir (Enders, 1995: 311). Varyans ayrıştırma analizi, bir değişkendeki değişimin yüzde kaçının kendi gecikmeleri ve yüzde kaçının diğer değişkenlerden kaynaklandığını araştırmaktadır (Tar1, 2015: 469).

Tablo 5: Varyans Ayrıştırma Analizi Sonuçları

\begin{tabular}{cccccc}
\hline Dönem & BIST100 & EXC & BIST100'ün Varyans Ayrıştırmas1 & INT \\
\hline 1 & 100.0000 & 0.000000 & 0.000000 & 0.000000 & 0.000000 \\
2 & 98.89082 & 0.019940 & 0.204197 & 0.363366 & 0.521679 \\
3 & 95.03780 & 0.022186 & 0.545647 & 3.856446 & 0.537921 \\
4 & 92.65388 & 0.020069 & 0.861171 & 3.955503 & 2.509376 \\
5 & 91.50213 & 0.481462 & 1.494681 & 4.031778 & 2.489952 \\
6 & 87.78311 & 2.447508 & 1.750167 & 4.323128 & 3.696083 \\
7 & 82.62794 & 4.821608 & 1.644257 & 4.030227 & 6.875971 \\
8 & 72.48064 & 9.429447 & 1.654401 & 3.744780 & 12.69073 \\
9 & 61.77559 & 15.27753 & 1.414812 & 3.361046 & 18.17102 \\
10 & 54.11916 & 20.01804 & 1.163106 & 3.097099 & 21.60259 \\
\hline & & & & & \\
Dönem & BIST100 & EXC & GDP & INF & INT \\
\hline & 3.592617 & 96.40738 & 0.000000 & 0.000000 & 0.000000 \\
1 & 2.711968 & 96.29021 & 0.115013 & 0.000115 & 0.882693 \\
2 & 3.906022 & 95.06493 & 0.137909 & 0.010373 & 0.880764 \\
4 & 5.459223 & 92.65637 & 0.477575 & 0.482450 & 0.924384 \\
5 & 7.131693 & 90.01540 & 0.446217 & 1.430166 & 0.976528 \\
6 & 9.345649 & 87.34366 & 0.357877 & 1.414653 & 1.538158 \\
7 & 11.05430 & 84.85125 & 0.314378 & 1.627053 & 2.153024 \\
8 & 11.91483 & 82.71406 & 0.261208 & 1.892258 & 3.217642 \\
9 & 13.03615 & 80.91831 & 0.225483 & 2.218082 & 3.601971 \\
10 & 14.49248 & 78.92083 & 0.219864 & 2.476916 & 3.889915 \\
& & & & &
\end{tabular}


GSYH'nin Varyans Ayrıştırması

\begin{tabular}{cccccc} 
Dönem & BIST100 & EXC & GDP & INF & INT \\
\hline 1 & 4.867932 & 0.227238 & 94.90483 & 0.000000 & 0.000000 \\
2 & 6.056664 & 5.516438 & 84.83203 & 3.585656 & 0.009215 \\
3 & 19.04850 & 7.459198 & 66.15368 & 5.912093 & 1.426529 \\
4 & 27.07324 & 11.21060 & 55.45860 & 5.055756 & 1.201800 \\
5 & 22.48990 & 12.54875 & 58.59095 & 5.080197 & 1.290199 \\
6 & 21.98842 & 13.76545 & 58.64169 & 4.177770 & 1.426678 \\
7 & 26.52120 & 14.33852 & 51.31156 & 4.503031 & 3.325693 \\
8 & 28.04214 & 15.43310 & 48.83973 & 4.271909 & 3.413116 \\
9 & 24.42399 & 15.80372 & 52.22390 & 4.479269 & 3.069117 \\
10 & 23.30846 & 16.56068 & 53.25980 & 4.084029 & 2.787035 \\
\hline
\end{tabular}

\begin{tabular}{|c|c|c|c|c|c|}
\hline \multicolumn{6}{|c|}{ Enflasyonun Varyans Ayrıştırması } \\
\hline Dönem & BIST100 & EXC & GDP & INF & INT \\
\hline 1 & 2.096158 & 4.557613 & 6.256622 & 87.08961 & 0.000000 \\
\hline 2 & 3.509577 & 13.30427 & 2.999817 & 74.04899 & 6.137349 \\
\hline 3 & 8.816442 & 16.98681 & 1.809379 & 66.61802 & 5.769344 \\
\hline 4 & 20.77668 & 20.37496 & 1.353235 & 52.50381 & 4.991309 \\
\hline 5 & 35.49973 & 20.66006 & 1.618377 & 38.90048 & 3.321351 \\
\hline 6 & 44.04382 & 22.10711 & 1.221432 & 30.16330 & 2.464342 \\
\hline 7 & 48.19528 & 24.01392 & 1.034638 & 24.33704 & 2.419126 \\
\hline 8 & 50.34296 & 25.59724 & 0.880632 & 20.08798 & 3.091183 \\
\hline 9 & 52.00343 & 26.93332 & 0.704955 & 16.75163 & 3.606658 \\
\hline 10 & 53.21591 & 28.29076 & 0.592245 & 14.10023 & 3.800849 \\
\hline \multicolumn{6}{|c|}{ Faiz Oranının Varyans Ayrıştırması } \\
\hline Dönem & BIST100 & EXC & GDP & INF & INT \\
\hline 1 & 0.682012 & 5.714577 & 11.33083 & 4.388658 & 77.88392 \\
\hline 2 & 2.421707 & 3.151036 & 14.87929 & 3.135273 & 76.41269 \\
\hline 3 & 2.390594 & 2.044764 & 14.20247 & 2.256602 & 79.10557 \\
\hline 4 & 2.643017 & 3.602211 & 13.00390 & 1.987810 & 78.76306 \\
\hline 5 & 8.187477 & 5.472856 & 11.58684 & 1.899345 & 72.85349 \\
\hline 6 & 13.25382 & 6.543732 & 9.988581 & 1.745544 & 68.46833 \\
\hline 7 & 16.05636 & 7.743054 & 8.841415 & 1.759213 & 65.59996 \\
\hline 8 & 17.90008 & 8.875381 & 8.223041 & 1.966947 & 63.03455 \\
\hline 9 & 19.39880 & 10.23008 & 7.850304 & 2.260007 & 60.26080 \\
\hline 10 & 21.06762 & 11.51018 & 7.288156 & 2.524664 & 57.60938 \\
\hline
\end{tabular}

Varyans ayrıştırma sonuçlarının yer aldığı Tablo 5'e göre, birinci dönemde BIST100'de meydana gelen şokların \%100'ü kendisinden kaynaklanırken, on dönem sonra BIST100'de meydana gelen şokların \%54.12'si kendisinden, \%21.60'1 faiz oranından, \%20.02'si döviz kurundan, \%3.10'u enflasyondan ve \%1.16's1 ise GSYH'den kaynaklanmaktadır. Yani BIST100 ile faiz oran1 ve döviz kuru arasında bir ilişki bulunmaktadır. Bu da döviz kuru ve faiz oranından meydana gelecek bir değişmenin BIST100'ü etkileyeceği şekilde yorumlanabilmektedir. 
Döviz kuru açısından varyans ayrıştırma analizi sonuçlarına göre, birinci dönemde döviz kurunda meydana gelen şokların \%96.41'i kendisinden, \%3.59'u ise BIST100'den kaynaklanırken, on dönem sonra döviz kurunda meydana gelen şokların \% 78.92'si kendisinden, \%14.49'u BIST100'den, \%3.89'u faiz oranından, $\% 2.48$ 'i enflasyondan ve \%0.22'si ise GSYH'den kaynaklanmaktadır. Buna göre döviz kuru ile BIST100 arasında güçlü bir ilişkin varlığından söz edilebilir. GSYH açısından varyans ayrıştırma sonuçlarına göre, birinci dönemde GSYH'de meydana gelen şokların \%94.91'i kendisinden, \%4.87'si BIST100'den ve \%0.22'si döviz kurundan kaynaklanırken, on dönem sonra GSYH'de meydana gelen şokların \%53.26's1 kendisinden, \%23.31'i BIST100'den, \%16.56's1 döviz kurundan, $\% 4.08$ 'i enflasyondan ve \%2.79'u faiz oranından kaynaklanmaktadır. Yani GSYH ile BIST100 ve döviz kuru arasında diğer değişkenlere nispeten daha güçlü bir ilişki bulunmaktadır. Enflasyon açısından varyans ayrıştırma sonuçlarına göre, birinci dönemde enflasyonda meydana gelen şokların \%87.09'u kendisinden, \%6.26's1 GSYH'den, \%4.56's1 döviz kurundan ve \%2.10'u BIST100'den kaynaklanırken, on dönem sonra enflasyonda meydana gelen şokların \%14.10'u kendisinden, \%53.22'si BIST100'den, \%28.29'u döviz kurundan, \%3.80'i faiz oranından ve \%0.59'u GSYH'den kaynaklanmaktadır. Buna göre enflasyon ile BIST100 ve döviz kuru arasında güçlü bir ilişki bulunmaktadır. BIST100 ve döviz kurunda meydana gelecek değişimler enflasyon üzerinde oldukça güçlü bir etki yaratabilmektedir. Faiz oranı açısından varyans ayrıştırma sonuçlarına göre ise birinci dönemde faiz oranında meydana gelen şokların \%77.88'i kendisinden, \%11.33'ü GSYH'den, \%5.72'si döviz kurundan, \%4.39'u enflasyondan ve \%0.68'i ise BIST100'den kaynaklanırken, on dönem sonra faiz oranında meydana gelen şokların \%57.61'i kendisinden, \%21.07'si BIST100'den, \%11.51'i döviz kurundan, \%7.29'u GSYH'den ve \%2.53'ü enflasyondan kaynaklanmaktadır.

\section{SONUÇ}

1980'li y1llarda liberalleşme ve küreselleşme ile başlayıp, artan finansal entegrasyonla devam eden süreçte sermaye akımları hayli etkileyici boyutlara ulaşmıştır. Gelişmekte olan ülkeler fon akımlardan pay alma yarışında yer almaya çabasındadır. Bir yanda portföy çeşitlendirmesinin de sağlayacağ 1 avantajlarla yüksek getiri peşinde olan ve giderek artan sermaye birikimi; diğer yanda ise, yüksek getiri potansiyeline sahip gelişmekte olan ülkelerin cazip piyasaları karşımıza çıkmaktadır. Söz konusu piyasalardan birisi olarak Türkiye'de gerek yüksek cari açık problemi gerekse bu açığın kapatılmasında yetersiz kalınması nedeniyle sıcak para akımlarına olan ihtiyaç yüksektir.

Çalışma kapsamında Türkiye piyasasında BIST100'ün getirisinde değişime neden olan makroekonomik faktörlerin araştırılması amaçlanmaktadır. Çalışma, kullanılan yöntem ya da veri seti anlamında benzer çalışmaların bazılarından ayrışmaktadır. Yanı sıra, literatürdeki bazı benzerlerini ise son verilerle güncelleme amacı güdülmüştür. Böylece, daha önceki çalışmalarda ulaşılan bulguların bir doğrulaması veya varsa ayrışmaların tespit ve tartışılması imkânı doğabilecektir. BIST100 üzerinden hisse senedi getirisi ile makroekonomik 
değişkenler olarak seçilen ve literatürde sıklıkla başvurulan GSYH, döviz kuru, faiz oran1 ve enflasyon arasındaki ilişki 2003:Q1 ve 2018:Q3 dönemi için araştırılmaktadır. Bu amaçla, önce ADF ve KPSS birim kök testleri ile ZivotAndrews yapısal kırılmalı birim kök testi uygulanmış; daha sonra Gregory-Hansen eşbütünleşme ve Granger nedensellik analizleri yürütülmüştür. Ampirik bulgular, BIST100 ile makroekonomik faktörler arasında yapısal kırılmalar varlığında trendde kırılma modeline göre uzun dönemli eşbütünleşik ilişkinin varlığını ortaya koymaktadır. Yanı sıra, kısa dönemli olarak GSYH, faiz oranı ve BIST100'den enflasyona, BIST100'den GSYH ve faiz oranına ve faiz oranından GSYH'ye tek yönlü ve anlamlı nedenselliğin, uzun dönemli olarak ise BIST100 ile döviz kuru arasında çift yönlü nedenselliğin varlığına işaret etmektedir. Varyans ayrıştırma analizi sonuçlarına göre çalışma kapsamında elde edilen sonuçların beklentilerle ve literatürle uyumlu olduğu görülmektedir. Buna göre, BIST100 ile faiz oranı ve döviz kurunun en güçlü uzun dönemli açıklayıcı ilişkilere sahip olduğu görülmektedir. Ulaşılan bulgular 1şı̆̆ında gerek yatırımcılar gerekse politika yapıcılar açısından önemli çıkarımların olduğu söylenebilir. Yatırımcılar açısından ekonomik risk faktörlerinin değişken önemine odaklanarak bireysel piyasalardaki portföy performanslarının iyileştirebilmesinde etkili olabileceğini göstermektedir. Politika yapıcılar açısından ise, cari açığın kapatılmasında ve ülkeye yabancı sermaye girişinde son derece etkili olan hisse senedi piyasasının döviz kuru ve faiz oranı gibi makroekonomik değişkenler ile güçlü bir ilişkiye sahip olduğundan hareketle, makroekonomik değişkenler ile ilgili yapılacak bir düzenleme hisse senedi piyasası üzerinde etkili olacaktır. Dolayısıyla, makroekonomik değişkenlerde istikrarı sağlamaya dönük politikalar daha çok yatırımcının yurt içine çekilmesine katkı sağlayacaktır.

\section{Araştırma ve Yayın Etiği Beyanı}

Makalenin tüm süreçlerinde Yönetim ve Ekonomi Dergisi'nin araştırma ve yayın etiği ilkelerine uygun olarak hareket edilmiştir.

\section{Yazarların Makaleye Katkı Oranları}

Yazarlar çalışmaya eşit oranda katkı sağlamıştır

\section{Çıkar Beyanı}

$\mathrm{Bu}$ çalışmada herhangi bir potansiyel çıkar çatışması bulunmamaktadır.

\section{KAYNAKÇA}

Abugri, B.A. (2008). Empirical relationship between macroeconomic volatility and stock returns: Evidence from Latin American markets. International Review of Financial Analysis, 17(2), 396-410.

Açıkalın, S., Aktaş, R. ve Ünal, S. (2008). Relationships between stock markets and macroeconomic variables: an empirical analysis of the Istanbul Stock Exchange. Investment Management and Financial Innovations, 5(1), 8-16.

Aggarwal, R. (1981). Exchange Rates and Stock Prices, A Study of the US Capital Markets under Floating Exchange Rates. Akron Business and Economic Review, 12(4), 7-12.

Alper, D. ve Kara, E. (2017). Borsa İstanbul'da Hisse Senedi Getirilerini Etkileyen Makroekonomik Faktörler: BİST Sınai Endeksi Üzerine Bir Araştırma, Süleyman Demirel Üniversitesi İktisadi ve İdari Bilimler Fakültesi Dergisi, 22(3), 713-730. 
Altınbaş, H., Kutay, N. ve Akkaya, C. (2015). Makroekonomik Faktörlerin Hisse Senedi Piyasaları Üzerindeki Etkisi: Borsa İstanbul Üzerine Bir Uygulama. Ekonomi ve Yönetim Araștırmaları Dergisi, 4(2), 30-49.

Barakat, M. R., Elgazzar, S.H. ve Hanafy, K.M. (2016). Impact of Macroeconomic Variables on Stock Markets: Evidence from Emerging Markets. International Journal of Economics and Finance, 8(1), 195-207.

Barışık, S. ve Demircioğlu, E. (2006). Türkiye'de Döviz Kuru Rejimi, Konvertibilite, İhracat-İthalat İlișkisi (1980-2001). ZKÜ Sosyal Bilimler Dergisi, 2(3), 71-84.

Bilson, C.M., Brailsford, T.J. ve Hooper, V.J. (2001). The Explanatory Power Of Political Risk in Emerging Markets. (The Australian National University, Working Paper Series in Finance 99-04).

Chen N.F., Roll, R. ve Ross., S.A. (1986). Economic Forces and the Stock Market, Journal of Business, 59, 383-403.

Cheung, Y.W. ve Ng, L.K. (1997). International evidence on the stock market and aggregate economic activity. Journal of Empirical Finance, 5(1998), 281-296.

Darrat, A.F. (1990). Stock Returns, Money and Fiscal Policy. Journal of Financial and Quantitative Analysis, 25(3), 387-398.

Enders, W. (1995). Applied Econometric Time Series. New York: Iowa State University.

Fama E. F. (1990). Stock Returns, Expected Returns and Real Activity. The Journal of Finance, 45(4), 1089-1108.

Fama, E. F. ve Gibbons, M.R. (1982). Inflation, Real Returns and Capital Investment. Journal of Monetary Economics, 9(1982), 297-323.

Fama E. F. ve Schwert, G.W. (1977). Asset Returns and Inflation, Journal of Financial Economics, $5,115-46$.

Fernandez-Arias, E. (1994). The New Wave of Private Capital Inflows: Push or Pull?. (The World Bank International Economics Department, Policy Research Working Paper, No. 1312).

Geske R. ve Roll, R. (1983). The Fiscal and Monetary Linkage Between Stock Returns and Inflation, Journal of Finance, 38, 7-33.

Gregory, A. W. ve Hansen, B. E. (1996). Residual-Based Tests for Cointegration in Models With Regime Shifts, Journal of Econometrics, 70, 99-126.

Gujarati, D.N. ve Porter, D.C. (2012). Temel Ekonometri (Çev: Ü. Şenesen, G.G. Şenesen), İstanbul: Literatür Yayıncilık.

Kwon, C.S. ve Shin, T.S. (1999). Cointegration and causality between macroeconomic variables and stock market returns. Global Finance Journal, 10, 71-81.

Lintner, J. (1969). The Valuation of Risk Assets and the Selection of Risky Investments in Stock Portfolios and Capital Budgets: A Reply. The Review of Economics and Statistics, 51(2), 222-224.

Markowitz, H. (1952). Portfolio Selection. The Journal of Finance, 7(1), 77-91.

Mossin, J. (1966). Equilibrium in a Capital Asset Market. Econometrica, Journal of the Econometric Society, 34(4), 768-783.

Muradoğlu G., Berument, H. ve Metin, K. (1999). Financial crisis and changes in determinants of risk and return: An empirical investigation of an emerging market (ISE). Multinational Finance Journal, 3(4), 223-252.

Muradoğlu G., Taskin, F. ve Bigan, I. (2000). Causality between stock returns and macroeconomic variables in emerging markets. Russian \& East European Finance and Trade, 36(6), 33-53.

Öztürk, M. B., Kurt Gümüş, G., Taşkın, F. D. ve Çağlı, E. Ç. (2013). Petrol ve Doğalgaz Fiyatları İle İmalat ve Kimya-Petrol-Plastik Sektörlerinin Endeksleri Arasındaki İlişki, Niğde Üniversitesi IIBFF Dergisi, 6(2), 64-74.

Pramod-Kumar, N. ve Puja, P. (2012). The impact of macroeconomic fundamentals on stock prices revisited: An evidence from Indian data. Eurasian Journal of Business and Economics, 5(10), 25-44. 
Roll, R., ve Ross, S. A. (1980). An Empirical Investigation of the Arbitrage Pricing Theory. The Journal of Finance, 35(5), 1073-1103.

Sevüktekin, M. ve Çınar, M. (2014). Ekonometrik Zaman Serileri Analizi, Bursa: Dora Yayıncılık.

Sadeghzadeh, K. ve Elmas, B. (2018). Makroekonomik Faktörlerin Hisse Senedi Getirilerine Etkilerinin BIST'de Araştırılması, Muhasebe ve Finansman Dergisi, 2018(Ekim), 205-230.

Shafana, M. (2014). Macroeconomic variables effect on financial sector performance in Emerging Sri Lankan Stock Market. International Journal of Science and Research, 3(10), 227-231.

Sharpe, W. F. (1964). Capital Asset Prices: A Theory Of Market Equilibrium Under Conditions Of Risk. The Journal of Finance, 19(3), 425-442.

Sutrisno, B. (2017). Macroeconomic Variables and Sectoral Indices: Case in The Indonesian Stock Exchange. Etikonomi, 16(1), 71-80.

Şekeroğlu, G., Uçan, O. ve Acar, M. (2019). Enflasyon Ve Dış Ticaret Açığının Borsa Endeks Getirileri Üzerindeki Etkisi: Borsa İstanbul 100 Endeksinde Bir Uygulama, Muhasebe ve Finansman Dergisi, 82, 221-234.

Tangjitprom, N. (2012). Macroeconomic Factors of Emerging Stock Market: The Evidence from Thailand. International Journal of Financial Research, 3(2), 105-114.

Tarı, R. (2015). Ekonometri, Kocaeli: Umuttepe Yayınları.

Yeşildağ, E. (2016). Makroekonomik Faktörlerin Borsa İstanbul'daki Endeks Getirilerine Etkisinin Arbitraj Fiyatlama Modeli İle Analizi, Süleyman Demirel Üniversitesi Sosyal Bilimler Enstitüsü Dergisi, CİEP Özel Sayısı, 51-76.

Wang, L.R. ve Shen, C.H. (1999). Do Foreign Investments Affect Foreign Exchange and Stock Markets - The Case of Taiwan. Applied Economics, 31, 1303-1314.

Zivot, E. ve Andrews, D. W. K. (1992). Further Evidence on the Great Crash, the Oil-Price Shock, and the Unit-Root Hypothesis. Journal of Business Economic Statistics, 10, 251-270.

\section{SUMMARY}

The two known forms of capital flows are direct investments and portfolio investments. The general opinion and empirical findings in the literature are quite positive about the contribution of direct investments to the country of origin. On the other hand, portfolio investments are generally seen to be short-term and their benefits to the economy they come from are questionable. In fact, the sudden outflows of portfolio investments, which are considered hot money, can have quite devastating effects. Turkey, which is a high current account deficit and an economy in need due to hot money flows remain insufficient to cover the deficit question of direct investments. Also, not already deep enough to reach the weight of foreign investors in Turkey's stock market is known that at the level of $65-70 \%$. Under these circumstances, how Turkey against internal and external development of the stock market is not too difficult to predict precisely that. Therefore, the effects of local economic and financial variables on the stock market are frequently investigated. Of course, the factors that affect fund flows are not only local - also called local or attractive - factors. Many external factors - also called global or repulsive - are known to be effective. Therefore, it is not easy to predict the direction and time of capital flows, which are subject to the influence of a large number of variables, including highly complex relationships. Hence study aims to examine the relationship between macroeconomic variables and return BIST100 in Turkey. Most studies use macro indicators as explanatory forces for changes in stock returns. 
When the financial literature is analyzed, it is seen that there are two main approaches to explaining the changes in the return on assets. These approaches are Capital Asset Pricing Model (CAPM) and Arbitrage Pricing Model (APM). The CAPM proposed by Markowitz (1952) for effective portfolio selection was developed by Sharpe (1964), Mossin (1966) and Lintner (1969). In the model, only the market factor is considered as the factor affecting returns. APM was developed by Roll and Ross (1980) based on the suggestion of multi-factor models rather than single-factor models for more accurate analysis. According to APM, changes in the returns of stocks stem from the changes observed in macroeconomic factors. Macroeconomic variables, on the other hand, provide a multi-factor modeling and complement the missing aspect of CAPM.

Stock prices are sensitive to both domestic and international developments. Many macroeconomic factors are involved in the development of this sensitivity. In this context, the existence and the degree of the relationship between stocks and macroeconomic variables is an important issue for investors. There are many studies in the literature on the analysis of this relationship. Macroeconomic indicators that can be used to reflect the different dimensions of the economy and to explain the changes in stocks may vary. Commonly used factors in the studies in the literature are gross domestic product (GDP), industrial production index, fixed capital formation, unemployment rate, total savings, interest rate, LIBOR, inflation rate, oil and gold prices, exchange rate and foreign exchange reserves.

This study examines the relationship between BIST100 and exchange rate, interest rate, inflation and GDP. Obtained from the Central Bank of the Republic of Turkey and BIST database, the entire data set is quarterly, and runs between 2003Q1 and 2018Q3. In the economics literature, interactions between national and global macroeconomic indicators and stock market returns are examined by using various econometric models.

In the study, it is aimed to investigate the macroeconomic factors that cause changes in the BIST100 return in the market of Turkey. The study differs from some of the similar studies in terms of the method or data set used. In addition, it is aimed to update some of the similar ones in the literature with the latest data. Thus, it may be possible to confirm the findings obtained in previous studies or to identify and discuss the dissociations, if any. The relationship between stock return over BIST100 and GDP, exchange rate, interest rate and inflation, which are frequently used in the literature and selected as macroeconomic variables, is being investigated for the period 2003Q1 and 2018Q3. For this purpose, ADF and PP unit root tests and Zivot-Andrews structural fracture unit root tests were applied first; then Gregory-Hansen cointegration test and Granger causality test were conducted.

Empirical findings reveal the existence of a long-term cointegrated relationship between BIST 100 and macroeconomic variables according to trend breaks. In addition, there are bidirectional and significant causality, interest rate to exchange rate, BIST100 to GDP, as well as BIST 100, GDP and interest rate inflation to one-way and significant causality. The results of variance 
decomposition analysis are consistent with expectations and literature. Accordingly, it is seen that the variables with the strongest long-term explanatory relations with BIST 100 are interest rate and exchange rate.

The findings provide important implications for both investors and policymakers. Focusing on the varying importance of economic risk factors for investors, it demonstrates that it can be effective in improving portfolio performances in individual markets. As for policy makers, a regulation on macroeconomic variables will have an impact on the stock market, as it has a strong relationship with macroeconomic variables such as the exchange rate and interest rate of the stock market, which is very effective in closing the current deficit and entering foreign capital into the country. Therefore, policies aimed at stabilizing macroeconomic variables will contribute to attracting more investors to the country. 